\title{
Primary Care Clinician Burnout and Engagement Association With Clinical Quality and Patient Experience
}

\author{
Rachel Willard-Grace, MPH, Margae Knox, MPH, Beatrice Huang, BA, \\ Hali Hammer, MD, Coleen Kivlahan, MD, MSPH, and Kevin Grumbach, MD
}

Background: Burnout and engagement are commonly conceptualized as opposite ends of a spectrum, and there is concern that high clinician burnout and lack of engagement may adversely impact patient care.

Methods: We matched self-reported data on burnout and engagement for 182 primary care clinicians with data on clinical quality (cancer screenings, hypertension and diabetes control) and patient experience (Clinician and Group Survey-Consumer Assessment of Healthcare Providers and Systems [CG-CAHPS] communication scores, overall rating, and likelihood to recommend the clinic).

Multivariable linear regression models examined burnout, engagement, or burnout-engagement phenotype (eg, high burnout-low engagement) as predictors of quality and patient experience.

Results: One-third of clinicians in this sample did not fall along the spectrum of low burnout-high engagement to high burnout-low engagement. Neither burnout nor engagement on their own was associated with quality or patient experience measures. However, clinicians with high burnout who also were highly engaged had the highest average ratings for all 3 patient experience domains: clinician communication, overall rating of the clinician, and overall rating of the clinic.

Discussion: The results of our study challenge the assumptions that burnout and engagement are opposite ends of a spectrum and that burnout or low engagement adversely impact quality of care and patient experience. Greater understanding is needed of how best to support dedicated clinicians who may provide quality care at the expense of their personal well-being. ( $\mathrm{J}$ Am Board Fam Med 2021;34:542-552.)

Keywords: Employee Engagement, Linear Models, Mental Health, Occupational Burnout, Patient Care, Primary Health Care, Self Report, Workforce

\section{Background}

The prevalence of burnout remains troublingly high among clinicians in the United States, especially in primary care. ${ }^{1}$ National health care goals have expanded to include the concept of the "quadruple

This article was externally peer reviewed.

Submitted 1 October 2020; revised 8 December 2020; accepted 21 January 2021.

From the Center for Excellence in Primary Care, Department of Family \& Community Medicine, University of California, San Francisco (RW-G, MK, BH, HH, CK, KG); School of Public Health, University of California, Berkeley (MK); San Francisco Department of Public Health (HH); UCSF Health, University of California, San Francisco (CK).

Funding: This project was supported by grant number R03HS026067 from the Agency for Healthcare Research and Quality. The content is solely the responsibility of the authors and does not necessarily represent the official views of the Agency for Healthcare Research and Quality.

Conflicts of interest: None. aim," with a proposed fourth aim being sustainability of practice for clinicians (including physicians and advance practice clinicians such as nurse practitioners and physician assistants) and staff., ${ }^{2,3}$

Employee engagement is frequently regarded as the inverse of burnout. ${ }^{4-8}$ However, cases have been observed among health care workers meeting the criteria for burnout whereas still deeply engaged in the care and treatment of their patients. Although many health systems use employee engagement measures such as the Net Promoter Score, the Gallup 12 survey, or the Utrecht Work Engagement Survey as a metric of organizational

Corresponding author: Rachel Willard-Grace, MPH, 1001 Potrero Ave., Ward 83, University of California San Francisco, San Francisco, CA 94110 (E-mail: Rachel.Willard@ucsf.edu). 
performance, ${ }^{10}$ limited research examines the relationship between burnout and engagement.

High burnout and low engagement are problems for reasons of concern about the well-being of health care workers, but there is also concern that they may adversely impact patient care. ${ }^{11}$ Quality of care and patient experience may suffer when clinicians and staff are demoralized, emotionally exhausted, or unenthusiastic about their place of work. Although an adverse relationship between clinician experience (eg, burnout, engagement) and the 3 other aims of the quadruple aim (quality, patient experience, and costs) is plausible and frequently asserted in commentaries about burnout, surprisingly little research has been performed in primary care. ${ }^{12}$

A few studies, many relying on clinician report, suggest that physician burnout or dissatisfaction are associated with more physician-perceived medical errors, ${ }^{13,14}$ unsafe prescribing behaviors, ${ }^{15}$ lower clinician-rated quality of care, ${ }^{16}$ poor patient communication, ${ }^{17}$ and poor patient adherence to treatment. ${ }^{18,19}$ However, studies relying on more objective quality measurement, such as medical records review, have failed to detect an association of quality of care with physician burnout, ${ }^{20,21}$ and findings on medical errors have been similarly mixed. ${ }^{22,23}$ The Minimizing Error, Maximizing Outcomes (MEMO) study found that although time pressure was associated with higher clinician burnout and lower quality of care, clinician burnout was not directly associated with lower quality. ${ }^{20}$ None of these studies used standard Health care Effectiveness Data and Information Set (HEDIS) quality measures. ${ }^{24}$

In the area of patient experience, patients are more likely to express satisfaction with their primary care experience when their clinicians or nurses report high job satisfaction. ${ }^{19,25,26}$ However, these studies used general work satisfaction items as predictors and not formal burnout or engagement scales such as the Maslach Burnout Inventory (MBI) or the Net Promoter Score. ${ }^{27}$ Studies in inpatient or behavioral health settings have found that burnout among clinicians or nurses is associated with lower patient satisfaction, but these results have not been replicated in primary care. ${ }^{28-32}$

A recently published research agenda for improving clinician wellness asserts that research investigating the relationship between burnout, care quality, and patient experience is a top priority, concurring with the lack of evidence on the impact of workforce burnout on the other elements of the quadruple aim. ${ }^{33}$ Research examining the association between burnout and engagement with other elements of the quadruple aim is vital to understanding whether interventions focused on burnout or engagement will be likely to move the other quadruple aim elements. If these associations are not robust, it is unreasonable to expect that strategies that reduce burnout or increase engagement will necessarily result in improvement in the other aims.

We examined the relationship between selfreported burnout and engagement of primary care clinicians working in 2 large, urban health systems. We then matched standard measures of clinical quality and patient experience at the level of the individual primary care clinician to investigate whether burnout and engagement were associated with the patient measures.

\section{Methods}

This study matched survey data on burnout and engagement collected in 2018 from primary care clinicians in 2 San Francisco primary care systems to clinical quality measures and patient experience measures summarized at the level of the individual clinician. The study protocol was approved by the University of California, San Francisco (UCSF) Committee on Human Research (1108048).

\section{Setting and Participants}

In February-March 2018, we surveyed clinicians and staff working in primary care clinics operated by a university health system (6 clinics) and a county health department (10 clinics) in San Francisco. Clinicians included physicians, nurse practitioners, and physician assistants responsible for a primary care panel. Clinicians were excluded if their ambulatory clinical effort was below $10 \%$ full-time equivalent (FTE) or if they practiced primarily at an urgent care or specialty site. Because of the FTE requirement, resident physicians and fellows were excluded from the analysis. Pediatrics sites were also excluded from analyses examining clinical quality because the quality measures used for this study did not all apply to children. All clinic personnel was salaried employees. 


\section{Measures}

Survey measures included 2 subscales from the Maslach Burnout Inventory General Survey: the 5item Emotional Exhaustion subscale and the 5-item Cynicism subscale. Each subscale produces a total score ranging from 0 to 30 , where 30 is the highest level of exhaustion or cynicism. A threshold of 16 for exhaustion and 11 for cynicism are standard markers for high exhaustion and cynicism, respectively. ${ }^{7}$ Consistent with previous research, we defined burnout as high if the respondent had a high score on either emotional exhaustion or cynicism and not high if they had lower scores on both emotional exhaustion and cynicism. ${ }^{14,34} \mathrm{We}$ also included a commonly used measure of employee engagement, used to create the Net Promoter Score, which asks about the likelihood that the respondent would recommend their clinic as a place to work (scale of 0 to 10 ). ${ }^{18}$ The conventional Net Promoter Score approach classifies respondents with scores of 9 and 10 as "promoters," 7 and 8 as "passively satisfied," and 6 or lower as "detractors." Consistent with the definition of "promoter," we defined engagement as high if the score was 9 to 10. The survey also collected data on position (eg, physician, nurse practitioner, or physician assistant) and tenure of employment.

We matched clinician responses from the 2018 survey with clinician-level quality and patient experience measures for the period of July 1, 2017-June 30, 2018. Five HEDIS quality measures ${ }^{24}$ abstracted from electronic health record registries were selected to represent clinical quality: up-todate breast, cervical, and colorectal cancer screening rates, hypertension control, and diabetes control. Patient eligibility for each registry measure differed by patient age, sex, and diagnosis, with cancer screening measures included for 26,000 patients, with a mean of 77 to 142 patients per clinician (depending on the measure), diabetes control included for 5200 patients with a mean of 31 patient per clinician, and hypertension control included for 15,900 patients with a mean of 88 patients per clinician. Each item was categorized dichotomously at the individual patient level (ie, up-to-date or not, in control or not), and the mean percentage of patients up-to-date or in control computed at the clinician level for each measure. After examination through principal components factor analysis, we created a composite cancer screening score at the clinician level calculated as an average of the breast, cervical, and colorectal cancer screening rates.

Patient experience measures from the Clinician and Group Survey-Consumer Assessment of Health care Providers and Systems (CG-CAHPS) included 4 items on clinician communication (provider explained things in a way you understood, provider listened carefully to you, provider showed respect for what you said, and provider spent enough time with you), a 1-item overall rating of the clinician, and 1 item on likelihood to recommend the clinic as a place to come for care. Response rates to the CGCAHPS were $12 \%$ to $13 \%$, which is consistent with rates reported by other organizations for routinely administered patient experience surveys. ${ }^{35-37}$ CGCAHPS measures for the clinicians in the study sample were derived from 9000 completed patient experience surveys, with a mean of 51 and a range of 5 to 325 patient responses per clinician. Consistent with CG-CAHPS reporting, the score at the clinician level for each item was computed as the percentage of survey respondents giving the clinician the highest possible rating for the measure. To create a composite clinician communication measure, we calculated a mean score across the 4 communication items, excluding surveys in which fewer than 3 items were answered. When a clinician had fewer than 5 patients for a particular clinical quality measure or fewer than 5 responses for a CG-CAHPS score, the measure was excluded from analysis due to concerns about the stability of the estimate.

Finally, we matched survey data to administrative data on clinical FTE and patient panel size. We adjusted panel size by system-calculated complexity scores $^{38}$ and FTE, producing a measure of complexity-adjusted panel size per clinical FTE.

\section{Analysis}

Data analysis was conducted using Stata version 13 (College Station, TX). ${ }^{19}$ We identified the clinicians meeting criteria for high burnout and high engagement. We then sorted clinicians into 1 of 4 mutually exclusive "phenotypes" of burnout-engagement: Low burnout-Low engagement, Low burnout-High engagement, High burnout-Low engagement, High burnout-High engagement. The individual burnout and engagement variables, as well as the composite phenotypes, were used as predictors of each of the dependent variables: the cancer composite score, diabetes control, hypertension control, clinician communication, rating of the clinician, and likelihood to 
recommend the clinic. After examining bivariate associations, we developed a multivariable linear regression model for each of the 6 dependent variables of clinical quality or patient experience with clinicians as the unit of analysis, adjusting error terms to account for clustering by clinic. For each dependent variable, we analyzed 3 models: (1) burnout (high/low) as the primary predictor, (2) engagement (high/low) as the primary predictor, or (3) burnout-engagement phenotype as the primary predictor. Models controlled for complexity adjusted panel size per clinical FTE, position (physician vs advanced practice clinician), years in the health system, FTE, health system, and whether the clinician worked at a residency teaching practice. We conducted a sensitivity analysis excluding individuals with fewer than 25 responses to patient experience surveys.

\section{Results}

The survey response rate was $80 \%$. A total of 182 clinicians were included in clinical quality analyses and 174 for the patient experience analysis. The majority ( $82 \%$ ) were physicians (Table 1 ). The complexity adjusted panel per clinical FTE was 1200 and clinicians reported about 0.5 clinical FTE on average. About half (51\%) reported either high exhaustion or high cynicism, meeting the criteria for high burnout. About a third (34\%) were classified as having high engagement on the likelihood to recommend the clinic as a place to work item. Using the 4 burnout- engagement phenotypes, $24 \%$ of respondents were categorized as low burnout-low engagement, $25 \%$ as low burnout-high engagement, $43 \%$ as high burnout-low engagement, and $9 \%$ as high burnout-high engagement. Clinicians had a mean of $72 \%$ of patients up to date on cancer screenings, $79 \%$ of patients with diabetes with well-controlled blood sugar, and $72 \%$ of hypertensive patients with blood pressure well controlled. Looking at the mean proportion of "top box" responses per clinician, clinicians had a mean of $87 \%$ top box ratings on Primary Care Clinician communication, $74 \%$ for overall ratings, and $80 \%$ on overall recommendation of the clinic (Table 1).

When examined as separate predictors, neither high burnout, high engagement, or the burnoutengagement phenotypes were significantly associated with any of the clinical quality measures, either in bivariate analysis (not shown) or multi-variate modeling with clustering by clinic and controlling for covariates (Table 2). This pattern remained consistent when we substituted the individual subscales of the Maslach Burnout Inventory (Emotional Exhaustion and Cynicism) rather than using them as a composite burnout measure (data not shown).

The burnout and engagement measures, when examined separately, also did not predict patient experience scores (Table 3). However, when comparing patient experience scores across the burnoutengagement phenotypes, clinicians with high burnout and high engagement had mean patient experience scores 7\% higher on clinician communication, $9 \%$ higher in overall rating of the primary care clinician, and $8 \%$ higher in overall likelihood to recommend the clinic compared with the mean scores for the other 3 phenotypes (Figure 1). In multivariate models using the phenotypes as the primary predictor of patient experience, the group of clinicians with high burnout and high engagement had significantly higher patient experience scores than the referent group of clinicians with high burnout and low engagement (Table 3). When sensitivity analysis was conducted excluding physicians with fewer than 25 responses to patient experience surveys, the pattern of results remained the same.

\section{Discussion}

The results of our study challenge 2 commonly held assumptions-that burnout and engagement are opposite ends of a spectrum, ${ }^{4,7,8}$ and that burnout has an adverse impact on quality-of-care processes and patient experience. One-third of clinicians in this sample did not fall along the spectrum of low burnout-high engagement to high burnout-low engagement. Almost a quarter (24\%) reported low burnout and low engagement, and $9 \%$ reported high burnout and high engagement. Consistent with several previous studies using objective measures of clinical quality such as medical record review, we failed to find an association between burnout or engagement and clinical quality measures. ${ }^{21,23}$

The quality measures included in the study (cancer screenings, diabetes control, hypertension control) are among the most common items used for primary care quality improvement and public reporting, and in these 2 health systems are tied to pay for performance incentives. As a result, these 
Table 1. Respondent Characteristics, $(n=186)$

\begin{tabular}{|c|c|c|}
\hline Characteristic & $\mathrm{N}(\%)$ & Mean \pm SD \\
\hline \multicolumn{3}{|l|}{ Position } \\
\hline Physician (non-resident) & $153(82.3)$ & \\
\hline Nurse practitioner/physician assistant & $33(17.7)$ & \\
\hline \multicolumn{3}{|l|}{ Tenure at time of survey } \\
\hline Less than 2 years & $38(20.5)$ & \\
\hline 3 to 10 years & $78(42.2)$ & \\
\hline More than 10 years & $69(37.3)$ & \\
\hline Complexity-adjusted panel per clinical FTE & & $1212 \pm 460$ \\
\hline Clinical FTE & & $0.48 \pm 0.30$ \\
\hline \multicolumn{3}{|l|}{ Health system } \\
\hline University-based & $84(45.2)$ & \\
\hline County-based & $102(54.8)$ & \\
\hline Work in a residency-teaching clinic & $90(48.4)$ & \\
\hline High burnout* & $89(51.2)$ & \\
\hline \multicolumn{3}{|l|}{ Emotional exhaustion (score category) ${ }^{\dagger}$} \\
\hline Overall score & & $15.2 \pm 7.4$ \\
\hline Low exhaustion ( 0 to 10$)$ & $49(26.3)$ & \\
\hline Moderate exhaustion (11 to 15 ) & $53(28.5)$ & \\
\hline High exhaustion (16 or more) & $84(45.2)$ & \\
\hline \multicolumn{3}{|l|}{ Cynicism (score category) $^{\dagger}$} \\
\hline Overall score & & $7.6 \pm 7.1$ \\
\hline Low cynicism (0 to 5$)$ & $94(50.5)$ & \\
\hline Moderate cynicism (6 to 10 ) & $40(21.5)$ & \\
\hline High cynicism (11 or more) & $52(28.0)$ & \\
\hline \multicolumn{3}{|l|}{ Engagement: Net Promoter Score (score category) ${ }^{\ddagger}$} \\
\hline Overall score & & $7.3 \pm 2.3$ \\
\hline Detractor $(0$ to 6$)$ & $46(24.7)$ & \\
\hline Passively satisfied (7 to 8 ) & $77(41.4)$ & \\
\hline Promoter (9 to 10$)$ & $63(33.9)$ & \\
\hline \multicolumn{3}{|l|}{ Burnout-engagement phenotypes } \\
\hline Low burnout-low engagement & $45(24.6)$ & \\
\hline Low burnout-high engagement & $44(24.0)$ & \\
\hline High burnout-low engagement & $78(42.6)$ & \\
\hline High burnout-high engagement & $16(8.7)$ & \\
\hline \multicolumn{3}{|l|}{$\begin{array}{l}\text { HEDIS patient quality measures: Proportion of } \\
\text { patients up-to-date or in control on HEDIS } \\
\text { quality measures, mean (S.D.) }\end{array}$} \\
\hline Cancer screening up to date & & $71.9 \%(11.5 \%)$ \\
\hline Breast cancer screening up to date & & $72.4 \%(14.3 \%)$ \\
\hline Cervical cancer screening up to date & & $73.4 \%(11.0 \%)$ \\
\hline Colorectal cancer screening up to date & & $69.6 \%(14.5 \%)$ \\
\hline Diabetes under control & & $79.0 \%(13.0 \%)$ \\
\hline Hypertension under control & & $72.0 \%(10.2 \%)$ \\
\hline $\begin{array}{l}\text { CG-CAPHS patient experience measures: } \\
\text { Proportion of top box scores on } \\
\text { CG-CAHPS measures, mean (S.D.) }\end{array}$ & & \\
\hline
\end{tabular}

Continued 
Table 1. Continued

\begin{tabular}{|c|c|c|}
\hline Characteristic & $\mathrm{N}(\%)$ & Mean \pm SD \\
\hline PCP communication & & $86.5 \%(12.8 \%)$ \\
\hline Rating of PCP & & $74.3 \%(17.1 \%)$ \\
\hline Recommend clinic ${ }^{\ddagger}$ & & $80.1 \%(16.3 \%)$ \\
\hline
\end{tabular}

CG-CAHPS, Clinician and Group Survey-Consumer Assessment of Healthcare Providers and Systems; FTE, full-time equivalent; HEDIS, Health care Effectiveness Data and Information Set; MBI, Maslach Burnout Inventory; PCP, primary care physician.

*The term "burnout" is defined as reporting either high exhaustion or high cynicism.

${ }^{\dagger}$ The MBI emotional exhaustion and cynicism subscales have a possible range of 1-30, with 30 being the most severe emotional exhaustion or cynicism.

${ }^{\ddagger}$ The Net Promoter Score refers to the likelihood to recommend clinic as place to work. This score has a possible range of $0-10$, with 10 being the most positive rating. Scores are classified as Detractor (0-6), Passively satisfied (7-8), or Promoters (9-10).

$\mathrm{SD}$, standard deviation.

health systems have invested in personnel, registry, and decision management systems targeted at improving these measures. Thus, the contributions of the individual primary care clinician are in the context of a broader practice team and organizational commitment to achieving quality goals on these measures. Future studies might examine whether quality metrics with less system-level support or pay-for-performance incentives might be more affected by clinician burnout. Alternatively, primary care clinicians experiencing burnout or lack of engagement with their clinic may be able to continue to provide high-quality patient care despite their negative work experience.

An intriguing result of our study is the association of the high burnout, high engagement burnoutengagement phenotype with better patient experience. Neither burnout nor engagement on their own was associated with patient experience measures. However, clinicians with high burnout who also were highly engaged had the highest average ratings for all 3 patient experience domains: clinician communication, overall rating of the clinician, and overall rating of the clinic. For clinicians reporting high engagement, high burnout was positively, not negatively, associated with patient experience.

To our knowledge, ours is the first study to investigate this interplay of clinician burnout and engagement as potentially predicting quality and patient experience in primary care. Other studies examining burnout alone have had mixed findings. For example, a recent study using a single-item measure of self-reported burnout found a negative association between primary care physician burnout and patient ratings of physician communication, but no association between burnout and overall patient rating of the physician. ${ }^{36}$

Our finding suggests that there is a phenotype of very committed, hard-working, and exhausted clinicians who are perceived by patients to be excellent, patient-centered clinicians, despite the toll that this disposition may take on the clinician's wellbeing. The co-occurrence of high burnout and high engagement may be a characteristic of missiondriven individuals who prioritize the importance or impact of their work over considerations of worklife balance. We found support for this interpretation in the feedback we received from our health system collaborators when we presented our findings. The near-universal response was, "I think I know who those people are." Members of our interpretive community were not surprised that patients of these clinicians reported better experience. One explained, "You may be exhausted, but when a patient is in front of you, that is all you see." A cautionary note was expressed that the outstanding care delivered by this group may come at a cost to the individual clinician.

In addition, the quarter of physicians in our sample who reported low burnout and low engagement demands further study as well, to understand if some clinicians may disengage as a protective mechanism against experiencing burnout. Interventions to reduce the burden of medical record documentation through approaches, such as team documentation, have shown promise to improve work experience. ${ }^{39,40}$ Notably, both systems in this study had begun fledgling team documentation programs, were supporting measurement and report back of work experience to guide practice-level improvement efforts, 
Table 2. Results of Multivariate Linear Regression Models for Composite Cancer Screening, Diabetes Control, and Hypertension Control, Adjusted for Covariates and Clustering by Clinic, $(\mathrm{n}=171-180) *$

\begin{tabular}{|c|c|c|c|c|}
\hline Variable & $\beta$ & Robust Standard Error & $95 \% \mathrm{CI}$ & $P$ value \\
\hline \multicolumn{5}{|c|}{ Dependent variable: Composite cancer screening } \\
\hline Model 1: High burnout ${ }^{\dagger}$ & -0.02 & 0.02 & $-0.05-0.02$ & .37 \\
\hline Model 2: High engagement ${ }^{\ddagger}$ & 0.02 & 0.02 & $-0.01-0.06$ & .21 \\
\hline \multicolumn{5}{|c|}{ Model 3: Burnout-engagement phenotypes } \\
\hline High burnout-low engagement & \multicolumn{4}{|c|}{ Reference } \\
\hline High burnout-high engagement & -0.02 & 0.02 & $-0.07-0.02$ & .27 \\
\hline Low burnout-low engagement & -0.01 & 0.02 & $-0.06-0.03$ & .54 \\
\hline Low burnout-high engagement & 0.03 & 0.03 & $-0.02-0.09$ & .20 \\
\hline \multicolumn{5}{|l|}{ Dependent variable: Diabetes control } \\
\hline Model 1: High burnout & -0.002 & 0.02 & $-0.05-0.05$ & .94 \\
\hline Model 2: High engagement & -0.02 & 0.02 & $-0.06-0.02$ & .36 \\
\hline \multicolumn{5}{|c|}{ Model 3: Burnout-engagement phenotypes } \\
\hline High burnout-low engagement & \multicolumn{4}{|c|}{ Reference } \\
\hline High burnout-high engagement & -0.03 & 0.03 & $-0.09-0.03$ & .32 \\
\hline Low burnout-low engagement & 0.004 & 0.03 & $-0.06-0.07$ & .90 \\
\hline Low burnout-high engagement & -0.01 & 0.03 & $-0.07-0.04$ & .65 \\
\hline \multicolumn{5}{|l|}{ Dependent variable: Hypertension control } \\
\hline Model 1: High burnout & 0.003 & 0.01 & $-0.02-0.03$ & .85 \\
\hline Model 2: High engagement & 0.003 & 0.02 & $-0.03-0.03$ & .86 \\
\hline \multicolumn{5}{|c|}{ Model 3: Burnout-engagement phenotypes } \\
\hline High burnout-low engagement & \multicolumn{4}{|c|}{ Reference } \\
\hline High burnout-high engagement & -0.04 & 0.02 & $-0.08-0.01$ & .13 \\
\hline Low burnout-low engagement & -0.03 & 0.02 & $-0.08-0.02$ & .29 \\
\hline Low burnout-high engagement & 0.004 & 0.01 & $-0.03-0.03$ & .80 \\
\hline
\end{tabular}

*This table illustrates the results of multivariate linear regression analysis. Three multivariate regression models are represented for each outcome in this table, with results adjusted for covariates and clustering by clinic. Burnout, engagement (likelihood to recommend the clinic), and the phenotypes were tested in separate regression models that included only 1 of these predictors at a time, along with the covariates. Covariates include complexity adjusted panel per clinical full-time equivalent, position (physician vs nurse practitioner), years in the health system, type of health system (county-based vs university-based), and whether working at a residency-teaching practice.

${ }^{\dagger}$ The term "high burnout" is defined as reporting either high exhaustion or high cynicism.

”The term "high engagement" is defined as a score of 9-10 on the "the likelihood to recommend clinic as place to work." This item has a possible range of $0-10$, which 10 being the most positive rating. This definition is consistent with scoring for the "Net Promoter Score," which defines a score of $9-10$ as being a promoter. CI, confidence interval.

and were investing in individual professional development plans during the period of the study data.

Our study has several limitations. It was conducted in an urban area among employed clinicians. Most clinicians worked part-time in clinical care, compared with $19 \%$ of physicians nationally working part-time, ${ }^{41}$ though our definition of clinical time does not include precepting residents in clinic or working in urgent care or inpatient settings. Of note, employed clinicians such as those in this study are growing in number nationally and now exceed the number who own their own practices. ${ }^{42}$ Findings may not be generalizable to other practice settings and regions. Although response bias is always a concern in studies including self-reported measures, our clinician survey response rate of $80 \%$ is much higher than that in most studies of health care workers. Our pragmatic, learning health system research approach took advantage of routinely administered patient experience (CG-CAHPS) surveys that are ubiquitous in health care and a key component of organization or clinician ratings. The cost of collecting primary patient survey data exclusively for this project would have far exceeded the study budget. Although the patient experience survey response rate was low, it was consistent with national averages. ${ }^{35,36}$ Our health system partners elected to use 1 measure of clinician engagement- 
Table 3. Results of Multivariate Linear Regression Models of Burnout and Engagement as Predictors of Patient Experience Scores, Adjusted for Covariates and Clustering by Clinic, $(\mathbf{n}=151)^{*}$

\begin{tabular}{|c|c|c|c|c|}
\hline Variable & Adjusted $\boldsymbol{\beta}$ & Robust Standard Error & $95 \% \mathrm{CI}$ & $P$ value \\
\hline \multicolumn{5}{|c|}{ Dependent variable: Proportion of patient ratings in top box for primary care provider communication } \\
\hline Model 1: High burnout ${ }^{\dagger}$ & 0.006 & 0.01 & $-0.02-0.03$ & .55 \\
\hline Model 2: High engagement ${ }^{\ddagger}$ & 0.008 & 0.01 & $-0.02-0.04$ & .54 \\
\hline \multicolumn{5}{|c|}{ Model 3: Burnout-engagement phenotypes } \\
\hline High burnout-low engagement & \multicolumn{4}{|c|}{ Reference } \\
\hline High burnout-high engagement & 0.04 & 0.02 & $0-0.08$ & .05 \\
\hline Low burnout-low engagement & 0.001 & 0.02 & $-0.04-0.04$ & .95 \\
\hline Low burnout-high engagement & -0.002 & 0.01 & $-0.03-0.03$ & .89 \\
\hline \multicolumn{5}{|c|}{ Dependent variable: Whether in top quartile of patient overall rating of primary care provider } \\
\hline Model 1: High burnout & 0.0005 & 0.01 & $-0.03-0.03$ & .97 \\
\hline Model 2: High engagement & 0.007 & 0.03 & $-0.05-0.07$ & .81 \\
\hline \multicolumn{5}{|c|}{ Model 3: Burnout-engagement phenotypes } \\
\hline High burnout-low engagement & \multicolumn{4}{|c|}{ Reference } \\
\hline High burnout-high engagement & 0.04 & 0.02 & $0.009-0.08$ & .02 \\
\hline Low burnout-low engagement & 0.01 & 0.03 & $-0.04-0.07$ & .62 \\
\hline Low burnout-high engagement & -0.0004 & 0.03 & $-0.06-0.06$ & .99 \\
\hline \multicolumn{5}{|c|}{ Dependent variable: Proportion of patient ratings in top box for recommendation of clinic } \\
\hline Model 1: High burnout & -0.003 & 0.02 & $-0.04-0.03$ & .87 \\
\hline Model 2: High engagement & 0.008 & 0.02 & $-0.03-0.04$ & .64 \\
\hline \multicolumn{5}{|c|}{ Model 3: Burnout-engagement phenotypes } \\
\hline High burnout-low engagement & \multicolumn{4}{|c|}{ Reference } \\
\hline High burnout-high engagement & 0.05 & 0.03 & $0.0002-0.10$ & .049 \\
\hline Low burnout-low engagement & 0.02 & 0.03 & $-0.05-0.09$ & .55 \\
\hline Low burnout-high engagement & 0.002 & 0.02 & $-0.04-0.04$ & .90 \\
\hline
\end{tabular}

*This table illustrates the results of multivariate logistic regression analysis. Three multivariate regression models are represented for each outcome in this table, with results adjusted for covariates and clustering by clinic. Burnout, engagement (likelihood to recommend the clinic), and the phenotypes were tested in separate regression models that included only 1 of these predictors at a time, along with the covariates. Covariates include complexity adjusted panel per clinical full-time equivalent, position (physician vs nurse practitioner), years in the health system, type of health system (county-based vs university-based), and whether working at a residency-teaching practice.

${ }^{\dagger}$ The term "high burnout" is defined as reporting either high exhaustion or high cynicism.

”The term "high engagement" is defined as a score of 9-10 on the "the likelihood to recommend clinic as place to work." This item has a possible range of $0-10$, which 10 being the most positive rating. This definition is consistent with scoring for the "Net Promoter Score," which defines a score of $9-10$ as being a promoter.

$\mathrm{CI}$, confidence interval.

the single item likelihood to recommend your clinic as a place to work question - that is used extensively across health care organizations in the United States ${ }^{43}$ Additional research is needed to determine whether our findings would hold with if other measures of engagement were used. This study did not include cost data, another important component of the quadruple $a^{2}{ }^{2}$ that guided the current study. Some research has suggested an association between work experience and increased cost through reduced productivity and medical errors, a subject that warrants additional research. ${ }^{44}$ Our study did not include inpatient settings; other research has found an inverse association between burnout and patient experience in that setting. ${ }^{28,32}$ Finally, our phenotype of clinicians with high burnout and high engagement was a small group, and our findings would be strengthened by validation using a larger sample. Additional mixed-methods research is needed to understand the prevalence of this phenotype, the robustness of the association with patient experience, and the distinguishing attributes, professionalism, and experiences of clinicians in this group.

In summary, our findings suggest that burnout and engagement are not opposites but are distinct dimensions of work experience. When work experience measures were examined separately, we did 
Figure 1. Mean proportion of top box ratings for each engagement-burnout phenotype, unadjusted, $(n=151)$. *Statistically significant difference from other groups $(P<.05)$. Abbreviations: PCP, primary care physician; Rec Clinic, Recommend Clinic.

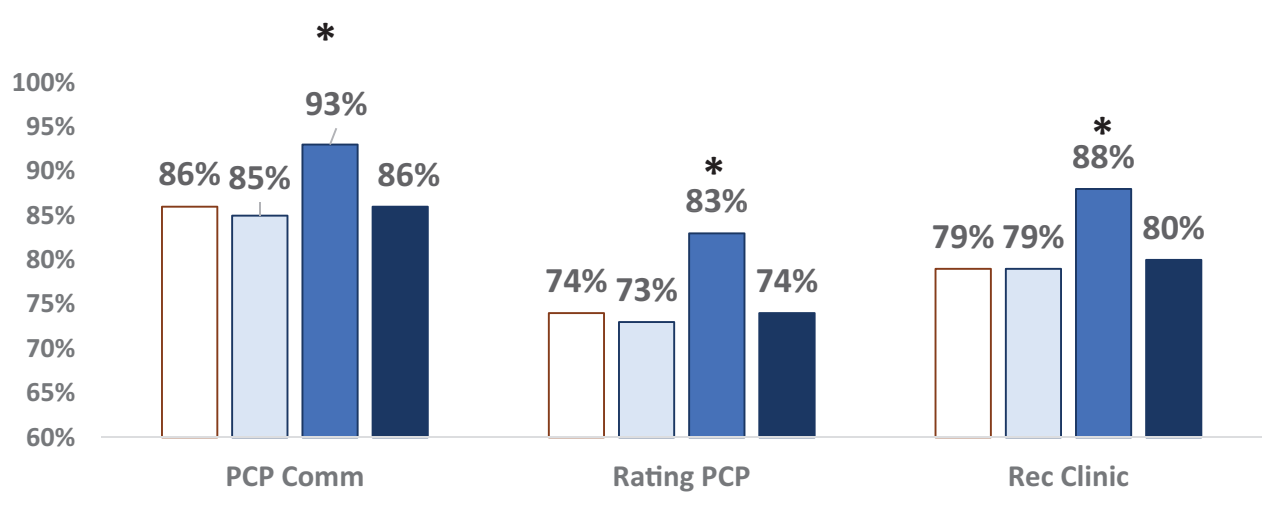

\section{$\square$ High burnout - Low engagement $\square$ Low burnout-Low engagement \\ High burnout - High engagement $\square$ Low burnout - High engagement}

not detect a significant association between burnout, engagement, quality of care, and patient experience. We did find that primary care clinicians who reported both high burnout and high engagement had significantly better patient experience scores than clinicians in other groups. Although the characteristics and coping strategies of this highly engaged but highly burned-out group warrant additional research, the key question may be less about whether burnout impacts quality of care and patient experience, but how we might better support those dedicated clinicians who pour their heart into patient care even at the expense of personal well-being.

The authors wish to acknowledge Christina Morata and Helen Gambrah, who provided data extraction expertise for this study, as well as health system partners who spearhead the System Transformation Evaluation Project survey in their health systems each year, including Robin George, Ellen Chen, Eric McNey, and other participants in our interpretive community.

To see this article online, please go to: http://jabfm.org/content/ 34/3/542.full.

\section{References}

1. Shanafelt TD, West CP, Sinsky C, et al. editors. Changes in burnout and satisfaction with work-life integration in physicians and the general US working population between 2011 and 2017. Mayo Clinic Proceedings; 2019. Elsevier.

2. Bodenheimer T, Sinsky C. From triple to quadruple aim: care of the patient requires care of the provider. Ann Fam Med 2014;12:573-6.

3. Sinsky CA, Willard-Grace R, Schutzbank AM, Sinsky TA, Margolius D, Bodenheimer T. In search of joy in practice: a report of 23 high-functioning primary care practices. Ann Fam Med 2013;11:272-8.

4. Shanafelt TD, Noseworthy JH. editors. Executive leadership and physician well-being: nine organizational strategies to promote engagement and reduce burnout. Mayo Clinic Proceedings; 2017: Elsevier.

5. Harter JK, Schmidt FL, Killham EA, Agrawal S. Q12 meta-analysis: The relationship between engagement at work and organizational outcomes. Omaha, NE: Gallup. 2009 Aug.

6. Cole MS, Walter F, Bedeian AG, O'Boyle EH. Job burnout and employee engagement: A meta-analytic examination of construct proliferation. J Manage 2012;38:1550-81.

7. Studar Q. Engagement is key to healing physician burnout. Modern Healthcare. 2015. Available from: https://www.modernhealthcare.com/article/20151015/ SUPPLEMENT/310159997/engagement-is-key-tohealing-physician-burnout. Accessed 1 October, 2020.

8. Becker's Hospital Review Staff. Physician burnout extinguishes physician engagement. Becker's Hospital Review. 2015. Available from https://www. beckershospitalreview.com/hospital-physicianrelationships/physician-burnout-extinguishes-physicianengagement.html. Accessed 1 October, 2020.

9. Anthony - McMann PE, Ellinger AD, Astakhova M, Halbesleben JR. Exploring different operationalizations of employee engagement and their relationships with workplace stress and burnout. Hum Resour Dev Q 2017;28:163-95.

10. Bakker AB, Schaufeli WB, Leiter MP, Taris TW. Work engagement: an emerging concept in occupational health psychology. Work Stress 2008;22:187-200.

11. Dyrbye LN, Shanafelt TD. Physician burnout: a potential threat to successful health care reform. JAMA 2011;305:2009-10. 
12. Abraham CM, Zheng K, Poghosyan L. Predictors and outcomes of burnout among primary care providers in the united states: a systematic review. Med Care Res Rev 2020;77:387-401.

13. West CP, Tan AD, Habermann TM, Sloan JA, Shanafelt TD. Association of resident fatigue and distress with perceived medical errors. JAMA 2009;302:1294-300.

14. Shanafelt TD, Bradley KA, Wipf JE, Back AL. Burnout and self-reported patient care in an internal medicine residency program. Ann Intern Med 2002;136:358-67.

15. Melville A. Job satisfaction in general practice: implications for prescribing. Soc Sci Med Med Psychol Med Sociol 1980;14A:495-9.

16. Loerbroks A, Glaser J, Vu-Eickmann P, Angerer P. Physician burnout, work engagement and the quality of patient care. Occup Med (Lond) 2017;67: 356-62.

17. Grol R, Mokkink H, Smits A, et al. Work satisfaction of general practitioners and the quality of patient care. Fam Pract 1985;2:128-35.

18. DiMatteo MR, Sherbourne CD, Hays RD, et al. Physicians' characteristics influence patients' adherence to medical treatment: results from the Medical Outcomes Study. Health Psychol 1993;12:93-102.

19. Weisman CS, Nathanson CA. Professional satisfaction and client outcomes. a comparative organizational analysis. Med Care 1985;23:1179-92.

20. Linzer M, Manwell LB, Williams ES, MEMO (Minimizing Error, Maximizing Outcome) Investigators, et al. Working conditions in primary care: physician reactions and care quality. Ann Intern Med 2009;151:28-36.

21. Rabatin J, Williams E, Baier Manwell L, Schwartz MD, Brown RL, Linzer M. Predictors and outcomes of burnout in primary care physicians. J Prim Care Community Health 2016;7:41-3.

22. Fahrenkopf AM, Sectish TC, Barger LK, et al. Rates of medication errors among depressed and burnt out residents: prospective cohort study. BMJ 2008;336:488-91.

23. Linzer M, Poplau S, Brown R, et al. Do work condition interventions affect quality and errors in primary care? Results from the Healthy Work Place Study. J Gen Intern Med 2017;32:56-61.

24. National Committee for Quality Assurance. Healthcare Effectiveness Data and Information Set (HEDIS) measures and technical resources. 2020. Available from: https://www.ncqa.org/hedis/measures/. Accessed November 27, 2020.

25. Linn LS, Brook RH, Clark VA, Davies AR, Fink A, Kosecoff J. Physician and patient satisfaction as factors related to the organization of internal medicine group practices. Med Care 1985;23: 1171-8.
26. Haas JS, Cook EF, Puopolo AL, Burstin HR, Cleary PD, Brennan TA. Is the professional satisfaction of general internists associated with patient satisfaction? J Gen Intern Med 2000;15:122-8.

27. Maslach C, Jackson SE, Leiter MP. Maslach Burnout Inventory Manual. 3rd ed. Palo Alto, Calif: Consulting Psychologists Press; 1996.

28. Garman AN, Corrigan PW, Morris S. Staff burnout and patient satisfaction: evidence of relationships at the care unit level. J Occup Health Psychol 2002;7:235-41.

29. Welp A, Meier LL, Manser T. Emotional exhaustion and workload predict clinician-rated and objective patient safety. Front Psychol 2014;5:1573.

30. Vahey DC, Aiken LH, Sloane DM, Clarke SP, Vargas D. Nurse burnout and patient satisfaction. Med Care 2004;42:II57-66.

31. Leiter MP, Harvie P, Frizzell C. The correspondence of patient satisfaction and nurse burnout. Soc Sci Med 1998;47:1611-7.

32. Halbesleben JRB, Rathert C. Linking physician burnout and patient outcomes: exploring the dyadic relationship between physicians and patients. Health Care Manage Rev 2008;33:29-39.

33. Dyrbye LN, Trockel M, Frank E, et al. Development of a research agenda to identify evidence-based strategies to improve physician wellness and reduce burnout identifying strategies to improve physician wellness and reduce burnout. Ann Intern Med 2017;166:743.

34. Shanafelt TD, Balch CM, Bechamps G, et al. Burnout and medical errors among American surgeons. Ann Surg 2010;251:995-1000.

35. Personal communication. Morato C. 21 August 2020.

36. Chung S, Dillon EC, Meehan AE, Nordgren R, Frosch DL. The relationship between primary care physician burnout and patient-reported care experiences: a cross-sectional study. J Gen Intern Med 2020;35:2357-8.

37. Tesler R, Sorra J. Agency for Healthcare Research and Quality. CAPHS survey administration: what we know and potential research questions. October 2017. Available at: https://www.ahrq.gov/sites/ default/files/wysiwyg/cahps/about-cahps/research/ survey-administration-literature-review.pdf. Accessed 1 October, 2020.

38. Rajkomar A, Yim JWL, Grumbach K, Parekh A. Weighting primary care patient panel size: a novel electronic health record-derived measure using machine learning. JMIR Med Inform 2016;4:e29.

39. Shultz CG, Holmstrom HL. The use of medical scribes in health care settings: a systematic review and future directions. J Am Board Fam Med 2015;28:371-81. 
40. DeChant PF, Acs A, Rhee KB, et al. Effect of organization-directed workplace interventions on physician burnout: a systematic review. Mayo Clin Proc Innov Qual Outcomes 2019;3:384-408.

41. American Medical Group Associates \& Cejka Search. 2007 Physician Retention Survey: Supplemental Edition. https://c.ymcdn.com/sites/aspr.site-ym.com/ resource/resmgr/imported/2013-02_2007-AMGA Physician-Retention-Survey.pdf. Published 2008. Accessed June 10, 2018.
42. Henry TA. American Medical Association. Employed physicians now exceed those who own their practices. 2019. Available from: https://www.ama-assn.org/about/ research/employed-physicians-now-exceed-those-whoown-their-practices. Accessed 1 October, 2020.

43. Reichheld FF. The one number you need to grow. Harv Bus Rev 2003;81:46-55.

44. West CP, Dyrbye LN, Shanafelt TD. Physician burnout: contributors, consequences and solutions. J Intern Med 2018;283:516-29. 